\title{
Blood Flow Restriction: Cause for Optimism, But Let's Not Abandon The Fundamentals
}

\author{
Dan Lorenz, DPT, PT, ATC, $\operatorname{CSCS}^{1}$ a \\ 1 LMH Health/OrthoKansas \\ Keywords: strength training, sports physical therapy, bfr \\ https://doi.org/10.26603/001c.23725
}

\section{International Journal of Sports Physical Therapy}

Vol. 16, Issue 3, 2021

One of the most popular modalities in sports physical therapy in recent memory is blood flow restriction (BFR) training. The concept of BFR dates back to the 1960's, and BFR-related studies published in the literature started increasing in the early 2000's. Its close relative, ischemic preconditioning, had been used even earlier than the 2000's in non-traditional sports physical therapy populations, like cardiac disease, but is now being used as a recovery tool in sports medicine settings. As sports physical therapy professionals, we have a good reason to be excited about this modality. Many interventions we use or have used have little to no scientific basis or clinical research to support them. There are numerous trends that have a theoretical basis for use. Thus, it seems we tend to put practice before the scientific and/or clinical research support. BFR training has not only been supported scientifically regarding mechanisms of action in the literature, but also has support from clinical studies indicating that BFR helps to relieve pain, 1,2 improve aerobic capacity, ${ }^{3-6}$ reduce the deleterious effects of immobilization, ${ }^{7,8}$ improve bone healing, ${ }^{9-11}$ and assist in the care of impairments in specific diagnoses like ACL reconstruction. ${ }^{12,13}$

Given that muscle weakness and atrophy are common impairments after musculoskeletal injury, BFR enables the sports physical therapist to mitigate atrophy and muscle weakness under low load conditions in order to minimize stress to healing tissues. ${ }^{14}$ The number of studies on the subject matter in peer-reviewed journals has exploded in the last six or seven years. The author of this viewpoint presented on the topic in 2015 and it was a novel concept to the audience and received with skepticism - for many of the current reasons. It can be overwhelming to wade through the science, the clinical studies, and the myriad of other considerations regarding BFR - safety/efficacy, indications/ contraindications, cuff selection, etc. Complicating matters further is that whenever trendy interventions surface, it is tempting to use them for any and all populations - everyone wants the shiny new toy, so to speak. The danger of this approach, though, is that in lieu of using proven methods, it is enticing to utilize cutting edge approaches for any and all purposes. Therefore, the objective of this viewpoint is threefold. First, a review of physiologic responses to BFR compared to more traditional training methods will be discussed. Second, a summary of key considerations for BFR with particular emphasis on safety and risk of DVT's will be reviewed. Last, a brief discussion about potential clinical usage and recommendations for implementing BFR.

It is beyond the scope of this clinical viewpoint to go into detail about the neural, mechanical, and metabolic mechanisms of increased strength and hypertrophy. There are several excellent review articles: Patterson et al., ${ }^{15}$ Pearson et al., ${ }^{16}$ and Hwang et al. ${ }^{17}$ for reviews on the mechanisms of BFR, and Schoenfeld et al., ${ }^{18}$ Kraemer et al., ${ }^{19}$ and Kraemer et al. $^{20}$ for reviews on traditional loading, respectively. To summarize, both traditional loading for strength and hypertrophy as well as low-load training with BFR cause increases in muscle building materials - growth hormone, Insulinlike growth factors (IGF's), Vascular Endothelial Growth Factor, mTORC1, and myogenic stem cells - all of which contribute to protein stimulus and muscle hypertrophy. ${ }^{21-23}$ When muscles are loaded up to $60 \%$ of one repetition maximum (1RM) or trained to failure, either could be aa potent stimulus for muscle hypertrophy. ${ }^{18}$ Strength is best trained with high loads, typically $>80 \% 1 \mathrm{RM}$ for $3-4$ sets in the 1-8 repetition range with long rest periods. In cases of the recovering athlete, high loads may not be appropriate or contraindicated. The evidence to date has shown that many of the benefits of traditional higher load training methods are similar or enhanced with low-load environments while using BFR. This is an exciting and clinically meaningful outcome. If we can get strength gains with loads that are as low as $20 \%$ of $1 \mathrm{RM}$, this is significant for just about anyone in practice.

Several concerns are frequently raised regarding the risk of deep venous thrombosis (DVT)/safety and legality. The reader is referred to the recent paper by Bond et $\mathrm{al}^{24}$ discussed the risk of DVT's when using BFR. Additionally, the Wells Criteria for DVT risk is a good reference for this topic. ${ }^{25}$ The fear of DVT is, at this time, more fear over facts. The author of this clinical viewpoint is not aware of any cases where a DVT was caused by BFR training. In a case study $^{26}$ by Noto et al., a subject got an effort thrombosis

\footnotetext{
a Corresponding author:

danielslorenz@gmail.com
} 
in the upper extremity, but a review of the training in that study showed that the subject trained every day with occlusion for about an hour. Time under occlusion is an aspect of BFR that is a topic of debate. Surgical tourniquets are inflated to well over $100 \mathrm{mmHg}$ on average, applied for about 2 hours, and have a complication rate of $0.04 \% .^{27}$ Most studies maintain occlusion, while other studies have allowed reperfusion between exercises or sets. ${ }^{28}$ Patterson et al. ${ }^{15}$ suggest $5-10$ minutes of occlusion per exercise and suggest continuous or intermittent pressure. Discomfort is typically the reason for the need for reperfusion, particularly if higher pressures are being utilized. It is possible that allowing reperfusion between sets may allow greater volume to be achieved due to less discomfort. Depending how many exercises are being performed, the tolerance to the pressure of the subject, and whether or not failure is achieved, the author suggests that occlusion time be for about 10 minutes for resistance exercises. The author is not aware of any studies saying one should not go over 10 minutes, but current studies seem to show benefits are realized in 10 minutes. It appears that an occlusion time around 10 minutes is the "minimum effective dose" to realize the benefits of BFR. However, we do not know at this time if longer times are more efficacious or warranted. For aerobic conditioning, about 20 minutes is suggested, but again, we do not know if longer times are warranted. Most of the side effects are short-lived, such as petechiae, numbness, and potentially abrasions if the BFR cuff isn't appropriately applied. The most notable side effect is likely discomfort. It is professional duty and responsibility to educate oneself on the scientific reasoning of a modality or treatment, application, relative indications, contraindications, and side effects. It is the responsibility of sports physical therapists to appropriately educate our patients and obtain their consent to treatment. Finally, thorough documentation is imperative, with or without BFR. In summary, BFR is safe when used appropriately \& under proper safety guidelines.

BFR is approved in the practice acts for both physical therapists and athletic trainers by the APTA ${ }^{29}$ and NATA, 30 respectively. There is currently no requirement for certification, nor is there any one device that is required to be used in exclusivity. It is important for the sports physical therapist to check state practice acts and ensure that key stakeholders like physicians, administrators/supervisors, and legal counsel are educated on the science, application, risks, and benefits of using BFR. Ultimately, the decision may not be made by practicing clinicians, but being informed is the most pragmatic approach.

At this time, BFR is most recommended to attenuate losses in hypertrophy and strength in conditions when traditional, high loads are either not indicated nor appropriate given the pathology in question. In addition, post-operative conditions of the lower extremity or injuries requiring immobilization are ideal candidates for BFR. BFR has been shown to have an additive effect when used with neuromuscular electrical stimulation (NMES) $)^{31-33}$ and the sports physical therapist should consider using it as an adjunct to traditional use of NMES. BFR is helpful for reducing pain and increasing strength in those whose symptoms may be exacerbated by high loads, such as advanced osteoarthritis of the knee; 34,35 however, it should be noted that the ben- efit of BFR in this particular population is in question in regards to clinical outcomes. ${ }^{36}$ In the upper extremity, the benefits of improved strength and hypertrophy 37,38 may be realized in rotator cuff repairs, Bankart repairs, SLAP repairs, or bicep/pectoral tendon repairs, but there is a less data on diagnosis-specific benefits of BFR in the upper extremity. Regardless of diagnosis, BFR should be used as a supplement to or to augment traditional loading progressions rather than a replacement of these methods.

While it appears that higher arterial occlusion pressures (AOP) are more beneficial, a range of $40-80 \%$ of AOP could be used if greater pressures are not tolerated by the patient or athlete. AOP should be determined by either Doppler ultrasound or pulse oximetry in the absence of personalized systems. Loading should be anywhere from $20-40 \%$ of one repetition-maximum (1RM), and this could be determined by a 10RM estimate, using the uninvolved limb as reference, or a load equivalent to 2-3 on the RPE scale. Usually, a minimum of 2-3 sets but up to 5 sets per exercise are recommended with anywhere from $45-75$ repetitions per exercise. The lower end of this repetition scheme is assuming at least 1-2 sets are performed to failure. ${ }^{39}$ One or two sets to failure is encouraged to maximize the hypertrophic effects. ${ }^{39,40}$ While the primary indications are listed above, there is evidence that BFR can be used to augment aerobic training at $30-50 \%$ of heart rate reserve (HRR) through either walking or use of other cardiovascular activities such as cycling or elliptical trainers. ${ }^{3-7}$ Additionally, studies have shown a benefit of BFR for improvements in VO2 Max. ${ }^{41-44}$ The benefits of BFR for performance training are likely indirect. Strength is the foundation of athletic performance and, therefore, increasing strength should improve power, but this may or may not transfer to actual improvements in sports performance. Thus, more power during strength training exercises may not transfer to improvements in batting average, shot percentage, or rushing yards, for example. It is not recommended that BFR be used prior to explosive activities due to BFR exercises being performed at or near volitional fatigue. While it is early to make any definitive conclusions, there is some early evidence that ischemic preconditioning may enhance recovery after athletic performance, ${ }^{45-49}$ but evidence to the contrary exists as well. ${ }^{50,51}$

While BFR appears to be a very promising and exciting innovation in our field, it is important to keep in mind that accepted, proven training practices and principles are not abandoned. Prior to incorporation of BFR training clinicians should ask themselves several questions. Why are more traditional methods not working? Has traditional exercise been dosed and loaded correctly? Has the clinician adhered to the principle of progressive overload? Is there an issue with programming that is prohibiting making the desired improvements? When an athlete is appropriate for higher loading, they should have higher loads. BFR should augment or be a supplement to traditional training methods when appropriate, not a replacement. While there a number of encouraging, positive studies on BFR, we still have so much to learn. The author encourages the reader to investigate the science, mechanisms, applications, clinical usage, and seek answers to clinical inquiries - but continue using proven, evidence supported methods for resistance training. 
Submitted: April 01, 2021 CDT, Accepted: May 09, 2021 CDT 


\section{REFERENCES}

1. Korakakis V, Whiteley R, Epameinontidis K. Blood flow restriction induces hypoalgesia in recreationally active adult male anterior knee pain patients allowing therapeutic exercise loading. Phys Ther Sport. 2018;32:235-243. doi:10.1016/j.ptsp.2018.05.021

2. Giles L, Webster KE, McClelland J, Cook JL. Quadriceps strengthening with and without blood flow restriction in the treatment of patellofemoral pain: A double-blind randomised trial. Br J Sports Med. 2017;51(23):1688-1694. doi:10.1136/bjsports-20 16-096329

3. Abe T, Fujita S, Nakajima T, et al. Effects of lowintensity cycle training with restricted leg blood flow on thigh muscle volume and VO2Max in young men. $J$ Sports Sci Med. 2010;9:452-458.

4. Abe T, Sakamaki M, Fujita S, et al. Effects of lowintensity walk training with restricted blood flow on muscle strength and aerobic capacity in elderly subjects. J Ger Phys Ther. 2010;33:34-40.

5. Silva JCG, Neto EAP, Pfeiffer PAS, et al. Acute and chronic responses of aerobic exercise with blood flow restriction: A systematic review. Front Physiol. 2019;10:1239. doi:10.3389/fphys.2019.01239

6. Conceicao MS, Junior EMM, Telles GD, et al. Augmented anabolic responses after 8-week cycling with blood flow restriction. Med Sci Sport Exerc. 2019;51(1):84-93. doi:10.1249/mss.000000000000175 $\underline{5}$

7. Bennett H, Slattery F. Effects of blood flow restriction training on aerobic capacity and performance: A systematic review. J Strength Cond Res. 2019;33(2):572-583. doi:10.1519/jsc.0000000000 $\underline{002963}$

8. Kubota A, Sakuraba K, Sawaki K, Sumide T, Tamura Y. Prevention of disuse weakness by restriction of blood flow. Med Sci Sport Exerc. 2008;40(3):529-534. $\underline{\mathrm{d}}$ oi:10.1249/mss.0b013e31815ddac6

9. Takarada Y, Takazawa H, Ishii N. Applications of vascular occlusion diminish disuse atrophy of knee extensor muscles. Med Sci Sport Exerc. 2000;32(12):2035-2039. doi:10.1097/00005768-20001 2000-00011

10. Linero C, Choi S-J. Effect of blood flow restriction during low-intensity resistance training on bone markers and physical functions in postmenopausal women. J Exerc Scit Fit. 2021;19(1):57-65. doi:10.1016/ j.jesf.2020.09.001
11. Bittar ST, Pfeiffer PS, Santos HH, Cirilo-Sousa MS. Effects of blood flow restriction exercises on bone metabolism: A systematic review. Clin Physiol Funct Imaging. 2018;38(6):930-935. doi:10.1111/cpf.12512

12. Lambert B, Hedt CA, Jack RA, et al. Blood flow restriction therapy preserves whole limb bone and muscle following ACL reconstruction. Orthop J Sports Med. 2019;7(3suppl2):2325967119S0019. doi:10.1177/ 2325967119s00196

13. Hughes L, Rosenblatt B, Haddad F, et al. Comparing the effectiveness of blood flow restriction and traditional heavy load resistance training in the post-surgery rehabilitation of anterior cruciate ligament reconstruction patients: a UK National Health Service randomized controlled trial. Sports Med. 2019;49(11):1787-1805. doi:10.1007/s40279-01 9-01137-2

14. Ohta H, Kurosawa H, Ikeda H, Iwase Y, Satou N, Nakamura S. Low-load resistance muscular training with moderate restriction of blood flow after anterior cruciate ligament reconstruction. Acta Orthop Scand. 2003;74(1):62-68. doi:10.1080/00016470310013680

15. Patterson SD, Hughes L, Warmington S, et al. Blood flow restriction exercise position stand: considerations of methodology, application, and safety. Front Physiol. 2019;10:533. doi:10.3389/fphy $\underline{\text { s.2019.00533 }}$

16. Pearson SJ, Hussain SR. A review on the mechanisms of blood flow restriction resistance training-induced muscle hypertrophy. Sports Med. 2015;45(2):187-200. doi:10.1007/s40279-014-0264-9

17. Hwang PS, Willoughby DS. Mechanisms behind blood flow-restricted training and its effect toward muscle growth. J Strength Cond Res. 2019;Suppl1:S167-S179. doi:10.1519/jsc.00000000000 02384

18. Schoenfeld BJ, Grgic J, Ogborn D, Krieger JW. Strength and hypertrophy adaptations between low vs. high-load resistance training: a meta-analysis. $J$ Strength Cond Res. 2017;31(12):3508-3523. doi:10.151 9/isc. 0000000000002200

19. Kraemer W, Gordon SE, Fleck SI, et al. Endogenous anabolic hormonal and growth factor responses to heavy resistance exercise in males and females. Int J Sports Med. 1991;12(02):228-235. doi:1 $\underline{0.1055 / \mathrm{s}-2007-1024673}$ 
20. Kraemer WJ, Marchitelli L, Gordon SE, et al. Hormonal and growth factor responses to heavy resistance exercise protocols. J Appl Physiol. 1990;69(4):1442-1450. doi:10.1152/jappl.1990.69.4.14 $\underline{42}$

21. Bazgir B, Fathi R, Valojerdi M, et al. Satellite cells contribution to exercise mediated muscle hypertrophy and repair. Cell J. 2017;18:473-484.

22. Gavin TP, Drew JL, Kubik CJ, Pofahl WE, Hickner RC. Acute resistance exercise increases skeletal muscle angiogenic growth factor expression. Acta Physiol. 2007;191(2):139-146. doi:10.1111/j.1748-171 6.2007.01723.x

23. Song Z, Moore DR, Hodson N, et al. Resistance exercise initiates mechanistic target of rapamycin (mTOR) translocation and protein complex colocalization in human skeletal muscle. Sci Rep. 2017;7(1):5028. doi:10.1038/s41598-017-05483-X

24. Bond CW, Hackney KJ, Brown SL, Noonan BC. Blood flow restriction resistance exercise as a rehabilitation modality following orthopedic surgery: a review of venous thromboembolism risk. J Orthop Sports Phys Ther. 2019;49(1):17-27. doi:10.2519/josp t.2019.8375

25. Modi S, Deisler R, Gozel K, et al. Wells criteria for DVT is a reliable clinical tool to assess the risk of deep venous thrombosis in trauma patients. World J Emerg Surg. 2016;11:24. doi:10.1186/s13017-016-007 8-1

26. Noto T, Hashimoto G, Takagi T, et al. PagetSchroetter Syndrome resulting from thoracic outlet syndrome and KAATSU Training. Intern Med. 2017;56(19):2595-2601. doi:10.2169/internalmedicin e.7937-16

27. Odinsson A, Finsen V. Tourniquet use and its complications in Norway. J Bone Joint Surg Br. 2006;88(8):1090-1092. doi:10.1302/0301-620x.88b8.1 $\underline{7668}$

28. Fitschen PJ, Kistler BM, Jeong JH, et al. Perceptual effects and efficacy of intermittent or continuous blood flow restriction resistance training. Clin Physiol Func Imaging. 2014;34(5):356-363. doi:10.1111/cpf.12 100

29. https://www.apta.org/patient-care/interventions/ blood-flow-restriction. Accessed March 3, 2021.

30. https://www.boc-digital.org/bocatc/summer 201 8/MobilePagedArticle.action?articleId=1404065\#artic leId1404065. Accessed March 3, 2021.
31. Natsume T, Ozaki H, Saito AI, Abe T, Naito H. Effects of electrostimulation with blood flow restriction on muscle size and strength. Med Sci Sport Exerc. 2015;47:2621-2627. doi:10.1249/mss.00000000 00000722

32. Inagaki Y, Madarame H, Neya M, Ishii N. Increase in serum growth hormone induced by electrical stimulation of muscle combined with blood flow restriction. Eur J Appl Physiol. 2011;111:2715-2721. $\underline{\mathrm{d}}$ oi:10.1007/s00421-011-1899-y

33. Head P, Waldron M, Theis N, et al. Acute neuromuscular electrical stimulation (NMES) with blood flow restriction: The effect of restriction pressures. J Sport Rehabil. 2020;Jul 31:1-9.

34. Bryk FF, dos Reis AC, Fingerhut D, et al. Exercises with partial vascular occlusion in patients with knee osteoarthritis: A randomized clinical trial. Knee Surg Sports Traumatol Arthrosc. 2016;24(5):1580-1586. do i:10.1007/s00167-016-4064-7

35. Ferraz RB, Gualano B, Rodrigues R, et al. Benefits of resistance training with blood flow restriction in knee osteoarthritis. Med Sci Sport Exerc. 2018;50(5):897-905. doi:10.1249/mss.0000000000001 $\underline{530}$

36. Grantham B, Korakakis V, O’Sullivan K. Does blood flow restriction training enhance clinical outcomes in knee osteoarthritis: A systematic review and meta-analysis. Phys Ther Sport. 2021;49:37-49. do $\mathrm{i}: 10.1016 / \mathrm{j} . \mathrm{ptsp} .2021 .01 .014$

37. Bowman EN, Elshaar R, Milligan H, et al. Upperextremity blood flow restriction: The proximal, distal, and contralateral effects - a randomized controlled trial. J Shoulder Elbow Surg. 2020;29(6):1267-1274. do $\mathrm{i}: 10.1016 / \mathrm{j} . j \mathrm{je} .2020 .02 .003$

38. Yasuda T, Fujita S, Ogasawara R, Sato Y, Abe T. Effects of low - intensity bench press training with restricted arm muscle blood flow on chest muscle hypertrophy: A pilot study. Clin Physiol Func Imaging. 2010;30(5):338-343. doi:10.1111/j.1475-097x.2010.00 949.x

39. Lorenz D, Bailey L, Wilk K, et al. Current clinical concepts: Blood flow restriction training. J Ath Train. 2021. doi:10.4085/418-20

40. Morton RW, Sonne MW, Zuniga AF, et al. Muscle fibre activation is unaffected by load and repetition duration when resistance exercise is performed to task failure. J Physiol. 2019;597(17):4601-4613. doi:1 $\underline{0.1113 / j p 278056}$ 
41. Abe T, Fujita S, Nakajima T, et al. Effects of lowintensity cycle training with restricted leg blood flow on thigh muscle volume and VO2Max in young men. $J$ Sport Sci Med. 2010;9(3):452-458.

42. Conceicao MS, Junior EMM, Telles GD, et al. Augmented anabolic responses after 8 week cycling with blood flow restriction. Med Sci Sports Exerc. 2019;51(1):84-93. doi:10.1249/mss.000000000000175 $\underline{5}$

43. Karabulut M, Esparza B, Dowllah IM, Karabulut U. The impact of low-intensity blood flow restriction endurance training on aerobic capacity, hemodynamics, and arterial stiffness. J Sports Med Phys Fitness. December 2020. doi:10.23736/S0022-470 7.20.11526-3

44. Silva JCG, Domingos-Gomes JR, Freitas EDS, et al. Physiological and perceptual responses to aerobic exercise with and without blood flow restriction. $J$ Strength Cond Res. 2019;Publish ahead of print. doi:1 0.1519/jsc.0000000000003178

45. Arriel RA, de Souza HLR, da Mota GR, Marocolo $M$. Declines in exercise performance are prevented 24 hours after post-exercise ischemic conditioning in amateur cyclists. PLoS One. 2018;13(11):e0207053. do i:10.1371/journal.pone.0207053

46. Cheung C, Slysz J, Burr J. Ischemic preconditioning: Improved cycling performance despite nocebo expectation. Int J Sports Physiol Perform. 2019;Oct 11:1-7.
47. Lisbôa FD, Turnes T, Cruz RSO, Raimundo JAG, Pereira GS, Caputo F. The time dependence of the effect of ischemic preconditioning on successive sprint swimming performance. I Sci Med Sport. 2017;20(5):507-511. doi:10.1016/j.jsams.2016.09.008

48. Jeffries O, Waldron M, Pattison JR, Patterson SD. Enhanced local skeletal muscle oxidative capacity and microvascular blood flow following 7-day ischemic preconditioning in healthy humans. Front Physiol. 2018;9:463. doi:10.3389/fphys.2018.00463

49. Page W, Swan R, Patterson SD. The effect of intermittent lower limb occlusion on recovery following exercise-induced muscle damage: A randomized controlled trial. J Sci Med Sport. 2017;20(8):729-733. doi:10.1016/j.jsams.2016.11.015

50. Garcia C, da Mota G, Leicht A, Marocolo M. Ischemic preconditioning and acute recovery of performance in rugby union players. Sports Med Int Open. 2017;1(3):E107-E112. doi:10.1055/s-0043-1110 $\underline{82}$

51. Cerqueira MS, Kovacs D, Martins de França I, et al. Effects of individualized ischemic preconditioning on protection against eccentric exercise-induced muscle damage: a randomized controlled trial. Sports Health. February 2021. doi:10.1177/1941738121995414 